\title{
Computed tomography pneumocolon had a low sensitivity for detecting colorectal neoplasms
}

Miao YM, Amin Z, Healy J, et al. A prospective single centre study comparing computed tomography pneumocolon against colonoscopy in the detection of colorectal neoplasms. Gut 2000 Dec;47:832-7.

\section{QUESTION: How accurate is computed tomography (CT) pneumocolon for detecting colorectal neoplasms in patients scheduled for colonoscopy?}

Source of funding: no external funding.

For correspondence: Dr Z Amin, Department of Radiology, Chelsea and 369 Fulham Road, London SW10 9NH, UK. Fax $+44(0) 208$ 7468588 .

\section{Setting}

1 hospital in London, UK.

\section{Patients}

201 consecutive patients (mean age 71 y, 59\% women) receiving colonoscopy for detection of colorectal neoplasms. Exclusion criteria were age $<55$ years, history of inflammatory bowel disease, and family history of colon cancer in an asymptomatic patient.

Description of test and diagnostic standard Standard bowel preparation was done for all patients. A CT pneumocolon examination was done in the supine position for all patients and in the prone position for most patients. 2 radiologists reviewed the images and were blinded to any previous colonoscopic results. Colonoscopy was done $\geqslant 1$ hour after CT pneumocolon by 1 of 12 gastroenterologists blinded to the CT pneumocolon results. Follow up was done for 11 months to identify further neoplasms.

\section{Main outcome measures}

Number of colorectal neoplasms. Secondary outcome measures were number of invasive carcinomas and polyps, pain, and patient preference.

\section{Main results}

Of the 72 patients (36\%) with neoplasms, 13 had invasive carcinomas, 63 had polyps, and 4 had both. 118 polyps were found in 63 patients. CT pneumocolon detected $38 \%$ of the patients with neoplasms (table), $100 \%$ of the patients with invasive carcinomas, and 29\% of the patients with polyps. CT pneumocolon was associated with more pain than colonoscopy (median scores $3 v 1$, $\mathrm{p}<0.001)$ and the procedure took more time $(33 v 25$ min, $\mathrm{p}<0.001) .83$ patients preferred CT pneumocolon, 90 preferred colonoscopy, and 20 had no preference. Westminster Hospital.

\section{Conclusion}

Computed tomography pneumocolon had a low sensitivity for detecting colorectal neoplasms but a high sensitivity for detecting invasive carcinomas.

Characteristics on computed tomographic pneumocolon for patients receiving colonoscopy*

\begin{tabular}{lclcll} 
Characteristics & Sensitivity (95\% CI) & Specificity (CI) & +LR & -LR \\
Colorectal neoplasms & $38 \%(26$ to 50$)$ & $86 \%(79$ to 92$)$ & 2.69 & 0.73 \\
\hline Invasive carcinoma $(\mathrm{IC})$ & $100 \%(81$ to 100$)$ & $99 \%(97$ to 100$)$ & 100 & 0 \\
\hline IC or polyps $\geqslant 1 \mathrm{~cm}$, or both & $73 \%(56$ to 90$)$ & $94 \%(91$ to 98$)$ & 12.2 & 0.29 \\
\hline
\end{tabular}

*Abbreviations defined in glossary; LRs and Cls calculated from data in article.

\section{COMMENTARY}

New screening procedures always bring into play the concepts of sensitivity, specificity, and predictive value. Assessment of the new procedures for these features is crucial and should ideally be followed by randomised trials for efficacy in reducing morbidity and mortality. In some instances, higher sensitivity and earlier diagnosis may lead to tradeoffs with over detection and increased numbers of false positive results. Alternatively, a new test may not be superior to the current standard.

Miao et al have provided a carefully done, well described comparison of the sensitivity and specificity of CT pneumocolon and colonoscopy for the detection of colorectal neoplasia. Their results confirm those of several recent studies by using virtual colonoscopy..$^{1-3}$ The sensitivity of CT for invasive tumours is certainly good, but the new technology falls short in detecting polyps. Furthermore, colonoscopy was superior to CT pneumocolon for comfort level. The disutility of CT pneumocolon depends on the importance one places on polyps and their elimination, something that is believed to have led to a decline in the incidence of colorectal cancer in the US. ${ }^{4}$

Alfred I Neugut, MD, PhD Columbia University New York, USA

1 Rex DK, Vining D, Kopecky KK. An initial experience with screening for colon polyps using spiral CT with and without CT colography (virtual colonoscopy). Gastrointest Endose 1999;50:309-13.

2 Fenlon HM, Nunes DP, Schroy PC, et al. A comparison of virtual and conventional colonoscopy for the detection of colorectal polyps. N Engl J Med 1999;341:1496-503.

3 Hara AK, Johnson CD, Reed JE, et al. Detection of colorectal polyps with CT colography: initial assessment of sensitivity and specificity. Radiology 1997;205:59-65.

4 Winawer SJ, Zauber AG, Ho MN, et al. Prevention of colorectal cancer by colonoscopic polypectomy. The national polyp study workgroup. N Engl J Med 1993;329:1977-81. 